\title{
Uncertainty in availability generated by inventory management controls in a generic repairable item sustainment system
}

\author{
G. D. Sherman ${ }^{1} \quad$ K. R. Owen ${ }^{2} \quad$ A. H. Pincombe ${ }^{3}$ \\ A. Bender ${ }^{4}$
}

(Received 10 February 2012; revised 26 October 2012)

\begin{abstract}
For defence logistics, strategic planning is typically based on mean values. Supply flows are estimated from average throughputs, and supply chain resources are allocated to meet average demands. Operations management is also based on mean values. Mean-value based inventory management techniques are the preferred way to maintain the availability of spare parts. Recent research suggests that defence maintenance systems using such inventory management techniques are sensitive to stochastic variability in stock demand. We illustrate that these deliberate planning actions can lead to increased uncertainty in the prediction of output measures such as operational availability. We use Discrete Event Simulation as well as Design of Experiments
\end{abstract}

http://journal.austms.org.au/ojs/index.php/ANZIAMJ/article/view/5237 gives this article, (c) Austral. Mathematical Soc. 2012. Published November 15, 2012. ISSN 1446-8735. (Print two pages per sheet of paper.) Copies of this article must not be made otherwise available on the internet; instead link directly to this URL for this article. 
methods to model a maintenance system for a single type of repairable item. We demonstrate that the inclusion of inventory management leads to increased average availability of spare parts for a vehicle fleet. However, in some cases the variation in availability decreases the system's apparent reliability.

\section{Contents}

1 Introduction

C541

2 Inventory management processes

C542

3 Model outline

C543

4 Experimental procedures and measures

C544

5 Outcomes

C546

5.1 Experiment I-Baseline sensitivity . . . . . . . . . . C546

5.2 Experiment II-Inventory control . . . . . . . . . . . . C547

5.3 Experiment III-Control robustness . . . . . . . . . . . C549

6 Conclusion

C550

A ROP/ROQ formulae

C551

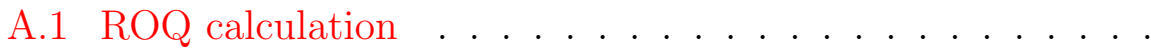

C551

A.2 ROP calculation . . . . . . . . . . . . . C551

A.2.1 Linear-moving average (mode 2 ) . . . . . . C552

A.2.2 Modified moving average (mode 3$) \ldots . . . . \quad$ C553

A.2.3 Single exponential smoothing algorithm (mode 4) . C553

A.2.4 Adaptive exponential smoothing (mode 5) . . . . C C554

B Input characteristics and ANOVA charts 
B.2 Experiment II-inventory control . . . . . . . . . C556

B.3 Experiment III — control robustness . . . . . . . . . . C559

References

C559

\section{Introduction}

Future failure rates and reliability are uncertain and forecasts are used to determine inventories of spare parts. Maintenance reliability depends upon the match between the failure rates and the availability of required parts. Hence, future demand for parts will also be uncertain. Some of this uncertainty is reduced over time as information accumulates. The risk of over investment can be reduced by making a reduced purchase of parts up front and supplementing the stock of parts by further purchases at different times. The balance between initial purchase and replenishment is particularly important for repairable parts (rotables) as they can make a significant contribution to vehicle availability. We use discrete event simulation to study this balance and to explore the effects of various inventory management processes.

We model the removal and replacement of damaged repairable components for vehicles in a fleet. The repairable component is sent off-site for repairs, and then stored in a storage facility until required. We focus on parameter values where the repair system is efficient, that is, where the number of repair servers and the stock of parts are just large enough to deal with repair demand as derived from mean values of stochastic variables such as inter-failure times and times to repair. This brings uncertainty: lack of vehicles leave the fleet unable to meet its objectives, while at other times there will be an excess of vehicles. Changes in the mean values over time can take the repair system from uncertain success to certain failure, until the repair capacity can be enlarged. The purchase of extra pieces of the repairable component can enable the fleet to meet its objectives in the period before the repair capacity is increased. This introduces uncertainties related to inventory management. 
We examine the problem in three stages of Monte-Carlo experimentation. In the first stage, we analyse how input uncertainty cascades through the maintenance model. The second stage incorporates an inventory management process and tests some stock re-ordering algorithms. In the third stage we assess the risk to availability for different values of mean time to repair.

\section{Inventory management processes}

Inventory management involves the calculation of the Re-Order Point (ROP) and the Re-Order Quantity (ROQ) which are calculated using demand forecasting algorithms. Such algorithms rely upon:

- demand rate, the amount of items consumed by customers, on average, per unit time;

- lead time, the delay between the time of re-order and that of supply;

- service level, the desired probability that a chosen level of safety stock will not lead to a stock out; and

- forecast error, an estimate of how far actual demand may be from forecasted demand.

The ROP/ROQ values can be based on events or on periods, triggering different replenishment times and actions. We include four common forecasting methods for inventory re-order calculations: linear (with Gaussian error calculation) [8], adjusted linear (with Gaussian error calculation and lead time factor), the exponential method $[3,4]$ and the adjusted exponential method [5]. Appendix A describes these algorithms. 


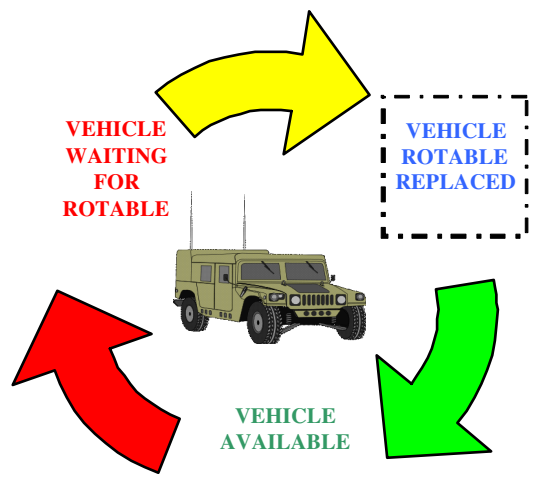

VEHICLE MAINTENANCE CYCLE
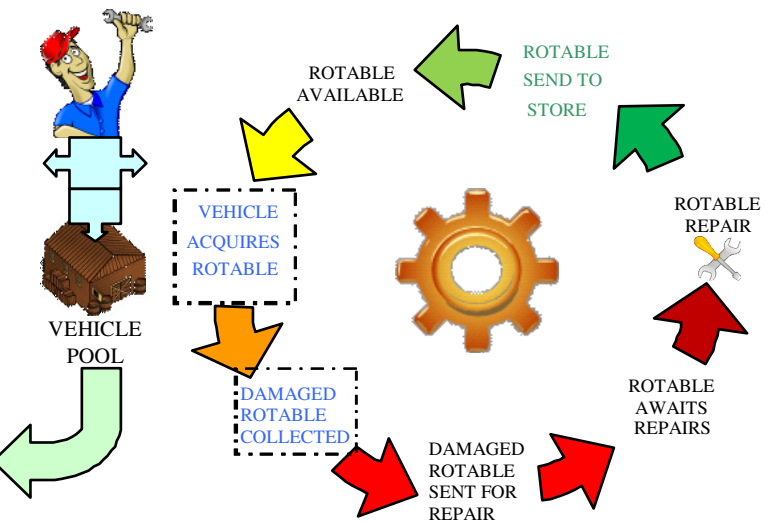

ROTABLE MAINTENANCE CYCLE

Figure 1: Actions within the maintenance model (alone) on vehicles and rotable entities.

\section{Model outline}

The model processes are shown in Figure 1. There are two entity flows. The left represents the possible activities of vehicles, the right those of rotable repair items. When a vehicle requires maintenance it waits both for maintenance services and for a replacement rotable, before being returned to available status. If a vehicle has to wait longer than a specified time (here 0 or 28 days), then another vehicle is released from a vehicle pool (if available) and the original failed vehicle will then be sent to the vehicle pool after rotable maintenance is completed.

The time between vehicle failures, transportation times to and from the workshop, and repair times, are sampled from representative distributions. This includes delays due to queuing for available human resources.

The model incorporates many parameters. We calibrate these to identify a region where the system functions close to a critical boundary in which fleet vehicle availability either falls away or is sustained. We then introduce a 
replenishment insertion point for repairable rotable items where the ready items are stored (shown at right in Figure 1) and use common inventory reorder algorithms to control this process.

Using both Mathworks ${ }^{\mathrm{TM}}$ SimEvents and Rockwell ${ }^{\mathrm{TM}}$ ARENA software combined with MATLAB ${ }^{\mathrm{TM}}$ we created two distinct discrete event simulation model environments to both verify and add flexibility to our design options. These software products were used previously in similar supply chain investigations such as those by Sherman et al. [9] with SimEvents and Wan and Zhao [6] with ARENA.

\section{Experimental procedures and measures}

The three main phases of experimentation are the following.

Experiment I-Baseline sensitivity. In the absence of replenishment, the maintenance model's behaviour is investigated against a range of parameters. This is used to narrow the regions in the parameter set for the next phase.

Experiment II-Inventory control. Four types of demand forecasting algorithms using a ROP/ROQ inventory management control process are individually introduced into the model. The focus of the experiment is the effects of differing algorithms and of lead time variance on the system.

Experiment III-Control robustness. A particular set of parameters from Experiment II is tested against values of Mean Time To Repair (MTTR) in order to gauge how the inventory management controls behave as availability varies.

In each of Experiments I, II, and III, if there are less than 25 vehicles in maintenance at simulation end, then the realisation is considered a success, otherwise it is a failure. A single time step in the simulation represents one 
day and each simulation run has 6000 time steps (days). Furthermore, the model has fifteen inputs of which three are options and twelve are parameter sets as listed in Tables 2 and 3 of Appendix B.1. Experiment I uses only a single realisation for each parameter combination. Experiments II and III use 100 random seeds for generating random distribution variates, to develop 100 realisations for each combination of parameters. The same set of 100 seeds are used for each parameter combination.

Some of the model diagnostics (outputs) of interest are the rotables on hand (the inventory stock level), the cumulative total of rotables ordered through inventory management, the number of vehicles in maintenance (vehicle unavailability), and the number in the vehicle pool. Figure 2 shows a typical output profile from the model. The realisation presented shows the inventory never stocking out (first graphic) where the just over 100 extra rotables are ordered (second graphic). The number of vehicles in maintenance (third graphic) stabilises and there are always some in the reserve pool (fourth graphic). This information could be used by inventory planners to estimate supply chain costs.

Figure 3 displays the number of vehicles in maintenance (vehicle unavailability) repeated over 100 simulations, comparing outcomes from two inventory management processes with all other model inputs equal. The left diagram displays the outcome of using an adjusted linear ROP/ROQ forecast technique. The right diagram shows the outcome from using an exponential forecast technique. The red lines show those simulation runs where the system fails (25 or more vehicles are in maintenance at simulation end), whereas the blue line shows when the system succeeds. These exemplar run outputs demonstrate that the exponential has on average fewer vehicles in maintenance and less chance of system failure. There is evidence of complex behaviour in the left diagram, with branching like phenomenon in unavailability at varying simulation times. Model outputs of this type were discussed by Hartmut [7] and Bender et al. [2]. The proportion of observed failures and other aggregated outputs form the basis of later analysis (Sections 5.2 and 5.3). 


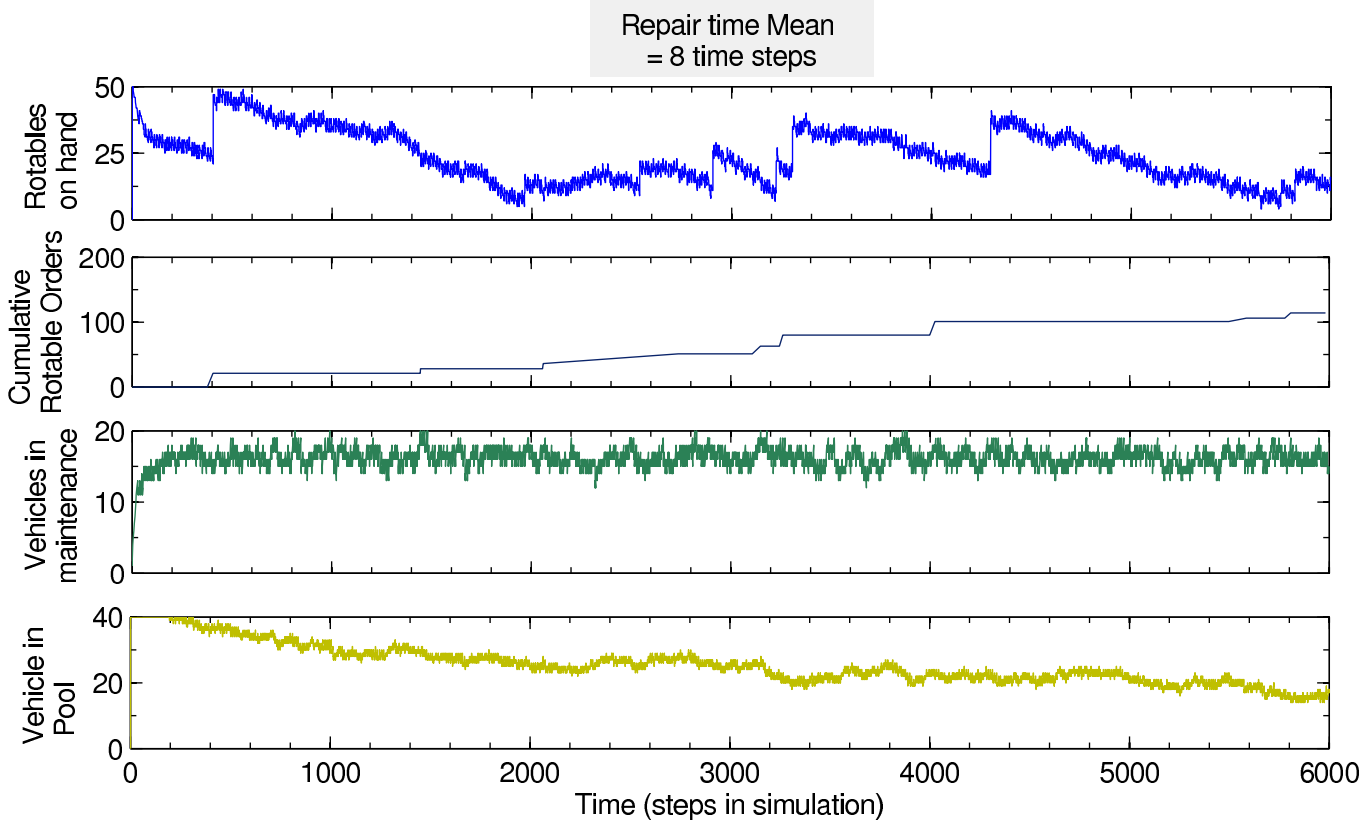

Figure 2: Sample simulation output giving four measures from the model.

\section{$5 \quad$ Outcomes}

\subsection{Experiment I-Baseline sensitivity}

Appendix B lists the parameters tested here. The objective is to define a region in parameter space where failure and success are both likely with any small deviation from each of the parameter values. Once a suitable region was found we applied ANOVA (Appendix B.1) to assess parameter values. Every parameter except the vehicle pool activation time ( 0 or 28 days) has a statistically significant effect on final availability levels. This is evident even in two factor interactions. 
100 Simulation runs (distinct seeds),

Inventory algorithm: Adjusted linear ROP/ROQ

LT distribution: uniform

MTTR distribution: normal

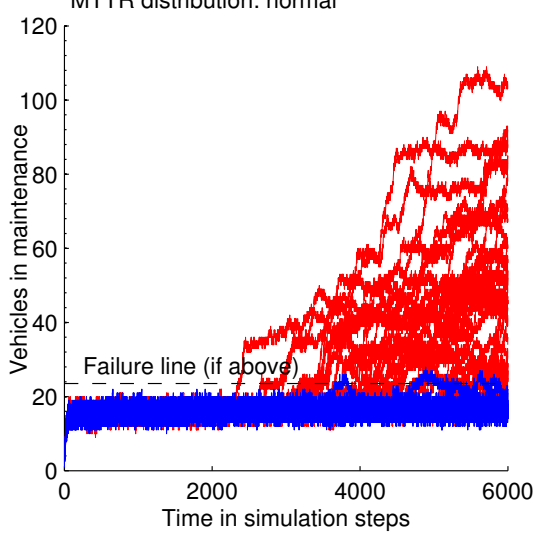

100 Simulation runs (distinct seeds), Inventory algorithm: Exponential LT distribution: uniform MTTR distribution: normal

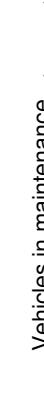$$
120
$$
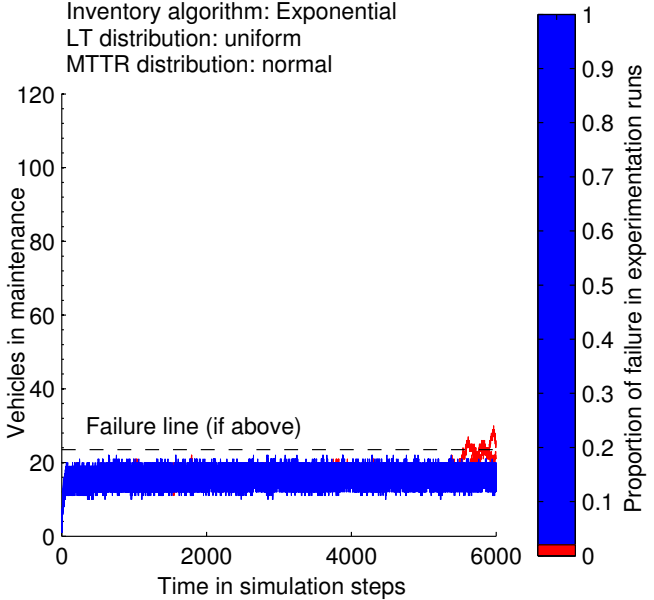

Figure 3: Number of vehicles in maintenance over 100 simulation runs for two inventory management processes.

\subsection{Experiment II-Inventory control}

This experiment introduces the four inventory management processes to the model. There are 336 parameter combinations tested, each realised 100 times. The aggregated data (across 100 realisations) for each parameter combination is given in Figure 4. This shows the propensity for system success for each inventory forecast algorithm (for all 336 combinations) against the average number of rotables ordered (left diagram). It also shows (right diagram) the time of inventory stock out (rotables) in those realisations that lead to system failure.

The aggregated outputs show evidence of clustering determined by the type of inventory algorithm used. These results demonstrate that the exponential type algorithms have a much improved availability, less chance of system failure (left diagram), and longer times on average for this to occur (right diagram). However, this algorithm also orders more stock and could be considered more expensive. The adjusted algorithms seem to require slightly less ordering 

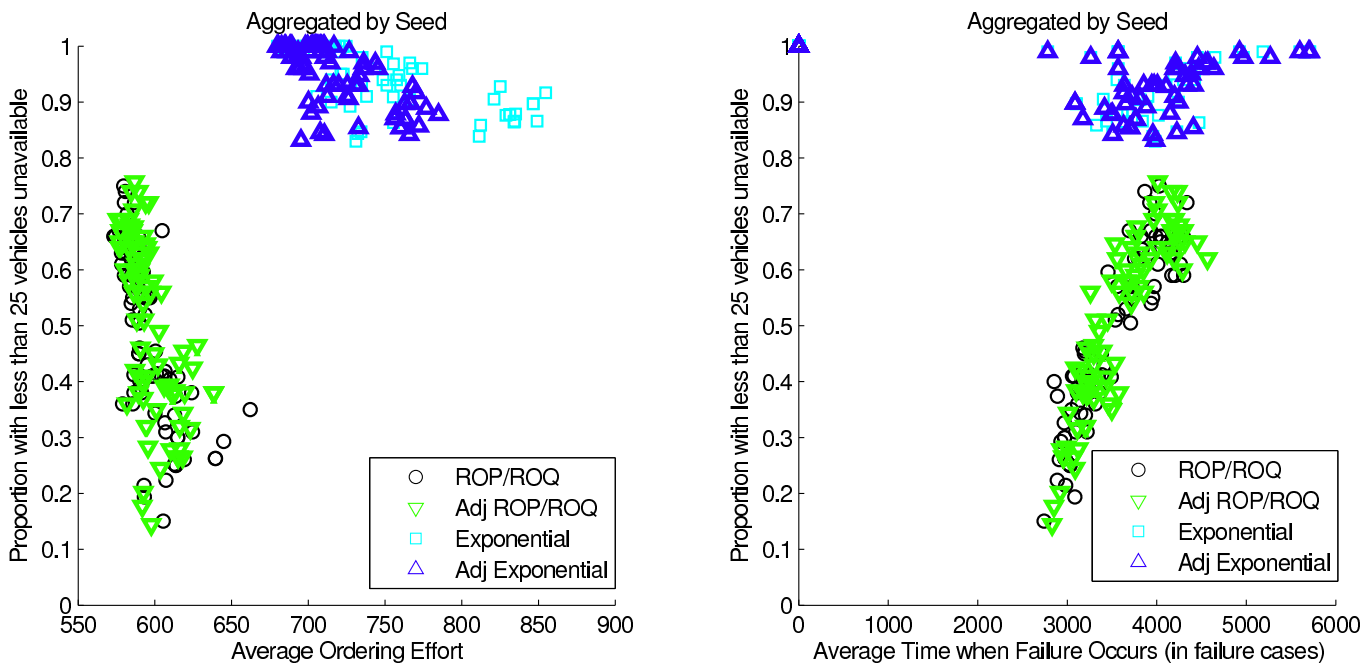

Figure 4: Proportion of system failures against orders made and time of system failure for each algorithm with event based ROP/ROQ calculation.

effort (cumulative rotable orders). The experiment was repeated with periodic calculation of ROP/ROQ (every 30 time steps) rather than being event based and results are shown in Figure 5 for comparison with Figure 4. The behaviour of the output changed considerably. The exponential algorithms failed much earlier and with greater likelihood than linear algorithms. There was a new set of very early failures, compared to the event based calculation case. The clustering of aggregated outputs no longer demonstrated a clear disparity between inventory management processes.

Of additional interest are uncertainties in availability that arise from waiting times for arrival of stock (lead time), choice of forecast method, when stock levels need to be assessed, and repair times in maintenance systems. The ANOvA charts of Appendix B.2 show that the variability in lead times and forecast method choice (when event calculated) impact availability considerably. 

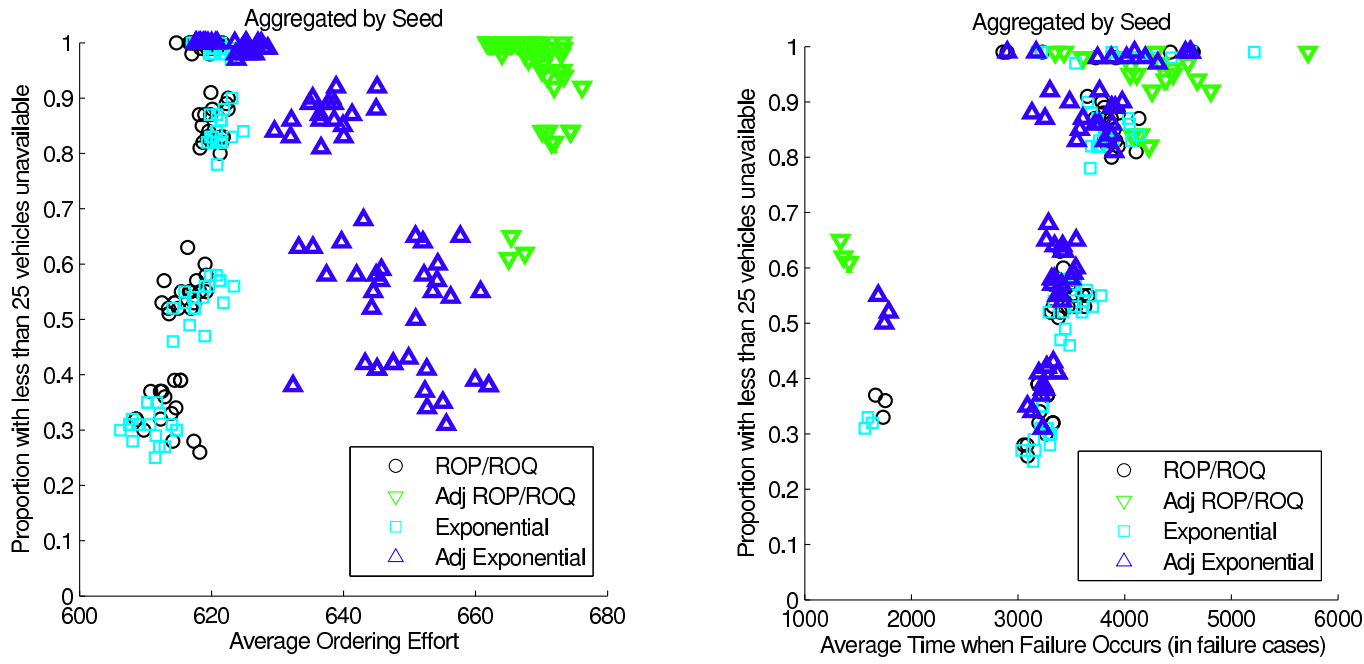

Figure 5: Proportion of system failures against time of system failure for each algorithm with periodic ROP/ROQ calculation.

\subsection{Experiment III-Control robustness}

The outcomes of this experiment are described by Figure 6. The top diagram measures average vehicle unavailability. The bottom diagram measures the likelihood of system failure against a variable MTTR. The diagrams are both similar in that with the absence of inventory management processes the risk is highest but also the condition against MTTR for non-failure or failure is more clearly defined (MTTR greater than 7.6). The linear ROP/ROQ algorithms display an increasing likelihood of vehicle unavailability and system failure against MTTR; however, this is more gradual with fleet losses more difficult to predict. The exponential algorithms are the safest option and also have higher MTTR values with similar risk to the lower values. Using no inventory management (least expensive) or the exponential algorithms (most expensive) showed less uncertainty in the availability outcomes. 

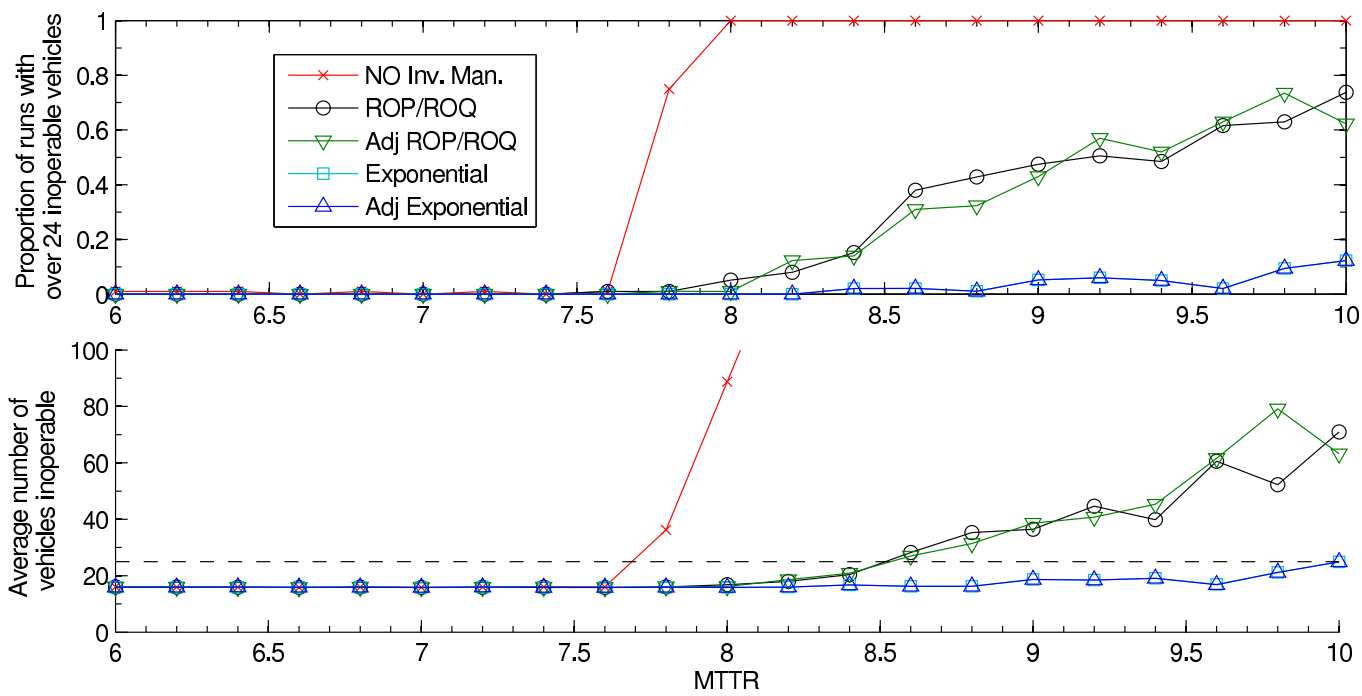

Figure 6: Comparison of inventory management techniques over changing MTTR against vehicle unavailability and proportion of failed runs at simulation end time.

\section{Conclusion}

In this investigation we developed and analysed a vehicle maintenance model, including four inventory management controls, in a parameter region where maintenance objectives could not be met without inventory management. The use of inventory management processes increased vehicle availability but achievement of maintenance objectives was uncertain for some processes. It was shown that exponential forecast algorithms ordered more stock and failed less often when calculations were event based. However, when calculations were periodic the choice of inventory process was less influential. 


\section{A $\mathrm{ROP} / \mathrm{ROQ}$ formulae}

In our experimentation the inventory management control is triggered in an event-based manner. The inventory management control process calculates the ROP based on the selected forecasting algorithm. The ROQ and reorder process is the same regardless of the selected forecasting algorithm. The placement of an order is dependent on a reset flag variable, which is set when an order is placed and reset when an order is received; this restricts the system to place only one order per period.

\section{A.1 ROQ calculation}

The ROQ parameter is based on the time and stock levels within the most recent period, defined from 0 (just after the last order was received) to $n$ (the most recent data point, or the point just before a new order is received). Hence, where LT is the mean Lead Time

$$
\mathrm{ROQ}=\left\lceil\frac{\Delta \operatorname{Stock}(0: n)}{\Delta \operatorname{Time}(0: n)} \times \mathrm{LT}\right\rceil .
$$

\section{A.2 ROP calculation}

The system will place an order immediately if the current stock level is at or below the current ROP, or the ROP calculated at the end of the previous period. The ROP will only be calculated if the current number of data points reaches or exceeds three. The ROP is generally based on five parameters:

- the Actual Usage (AU) between the most recent two data points;

- the Forecast Usage (FU) which gives an estimate of the usage based on a time average; 
- the Mean Absolute Deviation (MAD) which is the average deviation between $\mathrm{FU}$ and $\mathrm{AU}$;

- the Average Monthly Usage (AMU) which gives the rate of stock decline with time; and

- in some cases the alpha parameter, which gives a weighting for recent forecasts as opposed to historical forecasts.

These parameters are based on the time and stock levels within the most recent period, defined from 0 (just after the last order was received) to $\mathrm{n}$ (the most recent data point, or the point just before a new order is received). The value of $\mathrm{AU}$ is calculated when two or more data points exist, and is defined as

$$
\operatorname{AU}(n)=\operatorname{Stock}(n)-\operatorname{Stock}(n-1) .
$$

The AMU is similar to the ROQ definition,

$$
\operatorname{AMU}(n)=\frac{\Delta \operatorname{Stock}(0: n)}{\Delta \operatorname{Time}(0: n)} .
$$

The remaining parameters are iteratively calculated after three or more data points exist, and have a different definition for each algorithm.

\section{A.2.1 Linear - moving average (mode 2)}

The linear moving average forecasting algorithm defines

$$
\begin{aligned}
& \mathrm{FU}(\mathrm{n})=\frac{\mathrm{FU}(\mathrm{n}-1) \times \Delta \operatorname{Time}(0: n-2)+\mathrm{AU}(\mathrm{n}-1)}{\Delta \operatorname{Time}(0: n-1)} \\
& \mathrm{FU}(1)=\operatorname{AU}(1), \\
& \operatorname{MAD}(n)=\frac{\operatorname{MAD}(n-1) \times \Delta \operatorname{Time}(0: n-1)+|\mathrm{FU}(\mathrm{n})-\mathrm{AU}(\mathrm{n})|}{\Delta \operatorname{Time}(0: n)}, \\
& \operatorname{MAD}(1)=\frac{|\operatorname{AU}(1)-\operatorname{AU}(2)|}{\Delta \operatorname{Time}(0: 2)} \\
& \operatorname{ROP}(n)=\lfloor\operatorname{AMU}(n) \times \operatorname{LT}+\operatorname{K} \times \operatorname{MAD}(n)\rfloor
\end{aligned}
$$




\section{A.2.2 Modified moving average (mode 3)}

Here, FU and MAD are defined as for the linear moving average, but

$$
\operatorname{ROP}(n)=\lfloor\operatorname{AMU}(n) \times L T+K \times \operatorname{MAD}(n) \times \sqrt{L T}\rfloor .
$$

A.2.3 Single exponential smoothing algorithm (mode 4)

$$
\begin{aligned}
& \mathrm{FU}(\mathrm{n})=\alpha(\mathrm{n}) \times \mathrm{AU}(\mathrm{n}-1)+[(1-\alpha(\mathrm{n})] \times \mathrm{FU}(\mathrm{n}-1) \\
& \mathrm{FU}(1)=\mathrm{AU}(1) \alpha(\mathrm{n})=\frac{2}{\mathrm{n}+1}, \\
& \alpha(\mathrm{n})=\frac{2}{\mathrm{n}+1} .
\end{aligned}
$$

MAD is defined as per the moving average algorithm, and

$$
\operatorname{ROP}(n)=\lfloor\operatorname{AMU}(n) \times L T+K \times \operatorname{MAD}(n)\rfloor .
$$




\section{A.2.4 Adaptive exponential smoothing (mode 5)}

This adds the error parameter term FCSTERR,

$$
\begin{aligned}
& \operatorname{FCSTERR}(n)=0.1 \times[\operatorname{AU}(n-1)-\operatorname{FU}(n-1)] \\
& +0.9 \times \operatorname{FCSTERR}(n-1) \text {, } \\
& \operatorname{FCSTERR}(1)=0.1 \times[\operatorname{AU}(1)-\mathrm{FU}(1)], \\
& \operatorname{MAD}(n)=0.1 \times|[\operatorname{AU}(n-1)-\operatorname{FU}(n-1)]|+0.9 \times \operatorname{MAD}(n-1), \\
& \operatorname{MAD}(1)=\frac{|\operatorname{AU}(1)-\mathrm{AU}(2)|}{\Delta \operatorname{Time}(0: 2)}, \\
& \alpha(n)=\left|\frac{\operatorname{FCSTERR}(n)}{\operatorname{MAD}(n)}\right|, \\
& \alpha(1)=0.1 \text {, } \\
& \mathrm{FU}(\mathrm{n})=\alpha(\mathrm{n}) \times \mathrm{AU}(\mathrm{n}-1)+[1-\alpha(\mathrm{n})] \times \mathrm{FU}(\mathrm{n}-1), \\
& \mathrm{FU}(1)=\frac{\mathrm{AU}(1)-\mathrm{AU}(2)}{\Delta \operatorname{Time}(0: 2)},
\end{aligned}
$$

ROP is defined as per the single exponential smoothing algorithm.

\section{B Input characteristics and ANOVA charts}

Analysis of variance (ANOVA) [1] is a collection of statistical methods, and their associated procedures, in which the observed variance in a particular variable is partitioned into components attributable to different sources of variation. We used a fixed effects model and the list of inputs used are defined in Table 1. Tables 2 and 3 list the options and parameter values used for the three experiments. 
Table 1: Legend of Input types

Symbol Input

[A] Number of replacement and number of rotable removal services

[B] Vehicle/rotable mean failure rate

[C] Vehicle/rotable standard deviation on failure*

[D] Pool timeout length

[E] Rotable removal mean time

[F] Rotable replacement mean time

[G] Rotable repair mean time (MTTR)

[H] Number of repair services

[I] Rotable replacement time standard deviation*

[J] Rotable repair time standard deviation*

[K] Lead time (to receive order) standard deviation

$*$ denotes proportion of mean value

Table 2: Algorithm options in the three phases of experimentation.

\begin{tabular}{llll}
\hline Options & Exp I & Exp II & Exp III \\
\hline $\begin{array}{l}\text { Inventory } \\
\text { management }\end{array}$ & $\mathrm{n} / \mathrm{a}$ & Linear, & Linear, \\
algorithms & & Adjusted linear, & Exponential, \\
& & $\begin{array}{l}\text { Exponential, } \\
\text { Adaptive Smoothing }\end{array}$ & Adaptive Smoothing, \\
& & None \\
\hline $\begin{array}{l}\text { Lead time } \\
\text { distribution }\end{array}$ & $\mathrm{n} / \mathrm{a}$ & $\begin{array}{l}\text { Normal, Uniform, } \\
\text { Saturated Exponential, }\end{array}$ & Exponential \\
& & Offset Exponential, & \\
& & Truncated Exponential, & \\
& & Gamma, Weibull & \\
\hline $\begin{array}{l}\text { MTTR } \\
\text { distribution }\end{array}$ & \multirow{2}{*}{ Normal } & Normal, & Normal \\
& & Lognormal & \\
& & Uniform & \\
\hline
\end{tabular}


Table 3: Input types, values used for distributions.

\begin{tabular}{lccc}
\hline Input & Values & Values & Values \\
Legend & Exp I & Exp II & Exp III \\
\hline$[\mathrm{A}]$ & $1,2,3$ & 2 & 2 \\
{$[\mathrm{~B}]$} & $1.75,2.00, \ldots, 2.75$ & 2.5 & 2.5 \\
{$[\mathrm{C}]$} & $0.02,0.10,0.5$ & 0.25 & 0.25 \\
{$[\mathrm{D}]$} & 0,28 & 28 & 28 \\
{$[\mathrm{E}]$} & $4,5,6$ & 5 & 5 \\
{$[\mathrm{~F}]$} & $4,5,6$ & 5 & 5 \\
{$[\mathrm{G}]$} & $6,8,10$ & 10 & $6.0,6.2, \ldots, 9.8,10.0$ \\
{$[\mathrm{H}]$} & $3,4,5$ & 3 & 3 \\
{$[\mathrm{I}]$} & 0.1 & 0.1 & 0.1 \\
{$[\mathrm{~J}]$} & 0.1 & 0.25 & 0.25 \\
{$[\mathrm{~K}]$} & $\mathrm{n} / \mathrm{a}$ & $0.2,0.4,0.666,1$ & 1 \\
\hline
\end{tabular}

*denotes proportion of mean value

\section{B.1 Experiment I-Baseline sensitivity}

Table 4 lists the results of performing an ANOVA with two factor interactions on model output achieved in Experiment I.

\section{B.2 Experiment II-inventory control}

Figures 7 and 8 demonstrate the effect of model inputs tested in Experiment II upon availability in terms of amount and variance. These were derived from ANOVA effects and interaction plots. 
Table 4: Probability table of the F-statistic.

\begin{tabular}{|c|c|c|c|c|c|}
\hline Source & Sum Sq. & d.f. & Mean Sq. & $\mathrm{F}$ & Prob $>F$ \\
\hline$[A]$ & 802517534.3 & 4 & 200629383.6 & 36482.67 & 0.000 \\
\hline [B] & 557836049.0 & 4 & 139459012.3 & 25359.38 & 0.000 \\
\hline [C] & 32144.5 & 1 & 32144.5 & 5.85 & 0.016 \\
\hline [D] & 4438.5 & 1 & 4438.5 & 0.81 & 0.369 \\
\hline$[\mathrm{E}]$ & 35490027.8 & 2 & 17745013.9 & 3226.77 & 0.000 \\
\hline$[\mathrm{F}]$ & 35907284.2 & 2 & 17953642.1 & 3264.71 & 0.000 \\
\hline [G] & 6083180.7 & 2 & 3041590.4 & 553.09 & 0.000 \\
\hline$[\mathrm{H}]$ & 8062985.4 & 2 & 4031492.7 & 733.09 & 0.000 \\
\hline$[\mathrm{A}] \times[\mathrm{B}]$ & 8238144.2 & 16 & 514884.0 & 93.63 & 0.000 \\
\hline$[A] \times[C]$ & 782.0 & 4 & 195.5 & 0.04 & 0.998 \\
\hline$[A] \times[D]$ & 3694.7 & 4 & 923.7 & 0.17 & 0.955 \\
\hline$[A] \times[E]$ & 29270159.5 & 8 & 3658769.9 & 665.31 & 0.000 \\
\hline$[A] \times[F]$ & 29394225.9 & 8 & 3674278.2 & 668.13 & 0.000 \\
\hline$[\mathrm{A}] \times[\mathrm{G}]$ & 4372100.0 & 8 & 546512.5 & 99.38 & 0.000 \\
\hline$[\mathrm{A}] \times[\mathrm{H}]$ & 5796262.9 & 8 & 724532.9 & 131.75 & 0.000 \\
\hline$[\mathrm{B}] \times[\mathrm{C}]$ & 1376.2 & 4 & 344.0 & 0.06 & 0.993 \\
\hline$[\mathrm{B}] \times[\mathrm{D}]$ & 1841.4 & 4 & 460.4 & 0.08 & 0.987 \\
\hline$[\mathrm{B}] \times[\mathrm{E}]$ & 3106769.5 & 8 & 388346.2 & 70.62 & 0.000 \\
\hline$[\mathrm{B}] \times[\mathrm{F}]$ & 3112553.4 & 8 & 389069.2 & 70.75 & 0.000 \\
\hline$[\mathrm{B}]$ & 742960.1 & 8 & 92870.0 & 16.89 & 0.000 \\
\hline$[\mathrm{B}] \times[\mathrm{H}]$ & 1067460.1 & 8 & 133432.5 & 24.26 & 0.000 \\
\hline$[\mathrm{C}] \times[\mathrm{D}]$ & 14.4 & 1 & 14.4 & 0.00 & 0.959 \\
\hline$[\mathrm{C}] \times[\mathrm{E}]$ & 239.4 & 2 & 119.7 & 0.02 & 0.978 \\
\hline$[\mathrm{C}] \times[\mathrm{F}]$ & 209.3 & 2 & 104.6 & 0.02 & 0.981 \\
\hline$[\mathrm{C}] \times[\mathrm{G}]$ & 38.8 & 2 & 19.4 & 0.00 & 0.996 \\
\hline$[\mathrm{C}] \times[\mathrm{H}]$ & 121.6 & 2 & 60.8 & 0.01 & 0.989 \\
\hline$[\mathrm{D}] \times[\mathrm{E}]$ & 916.0 & 2 & 458.0 & 0.08 & 0.920 \\
\hline$[\mathrm{D}] \times[\mathrm{F}]$ & 1049.4 & 2 & 524.7 & 0.10 & 0.909 \\
\hline$[\mathrm{D}] \times[\mathrm{G}]$ & 308.2 & 2 & 154.1 & 0.03 & 0.972 \\
\hline$[\mathrm{D}] \times[\mathrm{H}]$ & 456.8 & 2 & 228.4 & 0.04 & 0.959 \\
\hline$[\mathrm{E}] \times[\mathrm{F}]$ & 993026.2 & 4 & 248256.6 & 45.14 & 0.000 \\
\hline$[E] \times[G]$ & 685803.6 & 4 & 171450.9 & 31.18 & 0.000 \\
\hline$[\mathrm{E}] \times[\mathrm{H}]$ & 938023.6 & 4 & 234505.9 & 42.64 & 0.000 \\
\hline$[\mathrm{F}] \times[\mathrm{G}]$ & 696785.0 & 4 & 174196.2 & 31.68 & 0.000 \\
\hline$[\mathrm{F}] \times[\mathrm{H}]$ & 956447.3 & 4 & 239111.8 & 43.48 & 0.000 \\
\hline$[\mathrm{G}] \times[\mathrm{H}]$ & 7781779.3 & 4 & 1945444.8 & 353.76 & 0.000 \\
\hline Error & 43686491.5 & 7944 & 5499.3 & & \\
\hline Total & 1586783684.7 & 8099 & & & \\
\hline
\end{tabular}



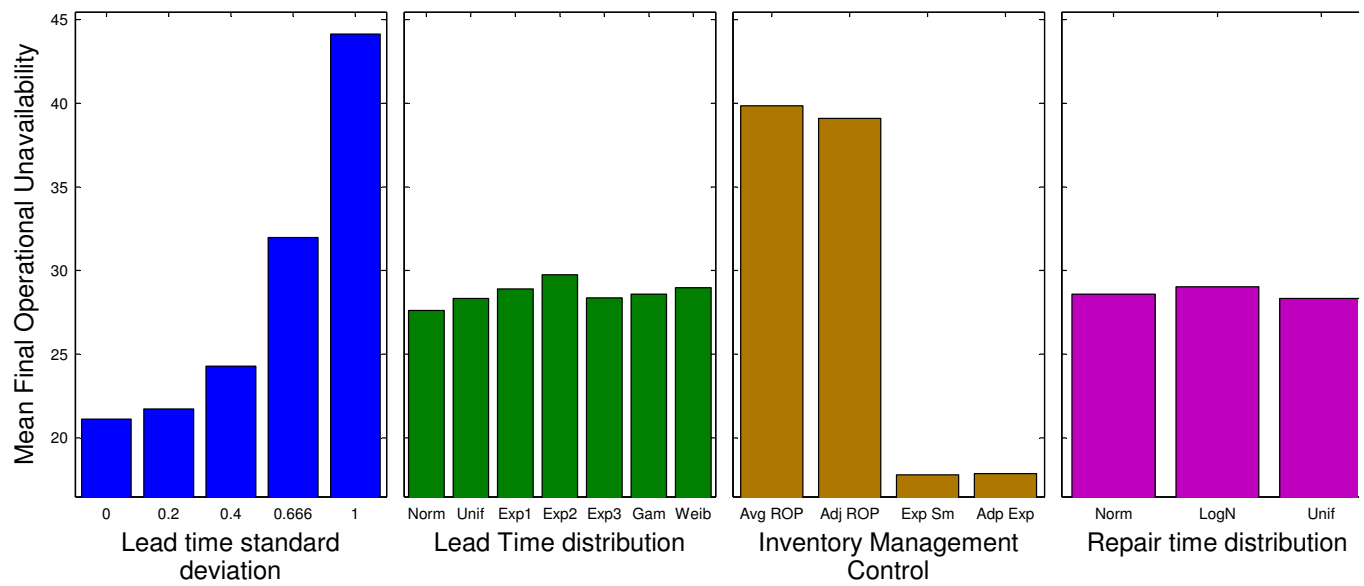

Figure 7: ANOVA chart 1-Final availability versus average parameter responses.
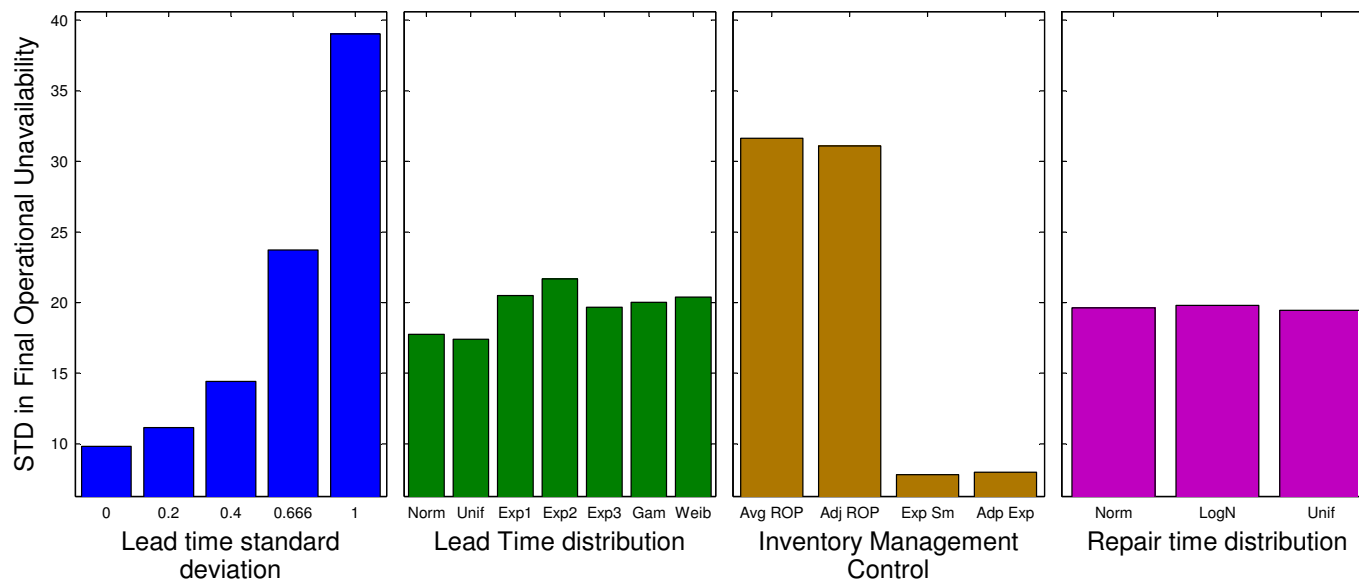

Figure 8: ANOVA chart 2-Final availability variance versus average parameter responses. 


\section{B.3 Experiment III-control robustness}

Explicit ANOVA was not necessary in this experiment as relatively few factors were tested. However, factor interactions are discussed and demonstrated in Section 5.3.

Acknowledgements The authors acknowledge support from the Graduate Industry Placement Program an agreement between the University of Adelaide and DSTO Edinburgh. This work is unclassified and authorised for public release.

\section{References}

[1] Anscombe, F. J. (1948) The Validity of Comparative Experiments. Journal of the Royal Statistical Society. Series A (General) 111 (3): 181-211. doi:10.2307/2984159 MR30181. C554

[2] Bender A., Pincombe A. H., Sherman G. D. (2009) Effects of decay uncertainty in the prediction of life-cycle costings for large scale military capability projects 18th World IMACS / MODSIM Congress, Cairns, Australia 13-17 July 2009. C545

[3] Brown, R. G Statistical Forecasting for Inventory Control McGraw-Hill, New York, 1959 C542

[4] Brown, Robert Goodell Smoothing Forecasting and Prediction of Discrete Time Series Englewood Cliffs, NJ: Prentice-Hall , 1963 C542

[5] Gardner, E. S., Jr., \& McKenzie, E. Forecasting trends in time series Management Science, 31, 1237-1246, 1985 C542

[6] Jie Wan, Cong Zhao, Simulation Research on Multi-Echelon Inventory System in Supply Chain Based on Arena, icise, pp.397-400, First 
International Conference on Information Science and Engineering, 2009 C544

[7] Hartmut Bossel Systems and models: Complexity, Dynamics, Evolution, Sustainability Books on Demand GmbH, 2007 C545

[8] Piasecki, David J. Inventory Management Explained: A focus on Forecasting, Lot Sizing, Safety Stock, and Ordering Systems OPS Publishing, 2009. C542

[9] Sherman G. D., Pincombe A. H., Bender A. (2009) Determining some of the triggers for early life cycle failure in decay affected logistic queueing simulation, Proceedings of the 9th Biennial Engineering Mathematics and Applications Conference, EMAC-2009 ANZIAM J., 51(E):C715-C729, 2010. http://journal.austms.org.au/ojs/index. php/ANZIAMJ/article/view/2604. C544

\section{Author addresses}

1. G. D. Sherman, Land Operations Division, DSTO Edinburgh 5111, South Australia.

mailto:gregory.sherman@dsto.defence.gov . au

2. K. R. Owen, Land Operations Division, DSTO Edinburgh 5111, South Australia.

3. A. H. Pincombe, Land Operations Division, DSTO Edinburgh 5111, South Australia.

4. A. Bender, Land Operations Division, DSTO Edinburgh 5111, South Australia. 